Vol. 11 (3): 599-610 (2021)

\title{
ADSORPTION OF BENALAXYL AND ATRAZINE IN FLY ASH THE COAL OF POWER PLANT (KOSOVO A) FROM AQUEOUS SOLUTIONS
}

\author{
Esad Behrami ${ }^{1}$, Kledi Xhaxhiu ${ }^{1}$, Bedri Dragusha ${ }^{2 *}$, Arianit Reka ${ }^{3}$, Adelaida Andoni ${ }^{1}$, \\ Xhuljeta Hamiti ${ }^{1}$, Spiro Drushku ${ }^{1}$ \\ ${ }^{l}$ University of Tirana, Faculty of Natural Sciences, Department of Chemistry, Tirana, Albania; \\ ${ }^{2 *}$ University of Prishtina, Faculty of Agriculture and Veterinary, Department of Pomology \\ and Viticulture, Prishtina, Kosovo; \\ ${ }^{3}$ University of Tetovo, Faculty of Natural Sciences and Mathematics, Ilinden n.n., 1200 Tetovo, \\ Republic of North Macedonia;
}

*Corresponding Author Bedri Dragusha, e-mail: bedri.dragusha@uni-pr.edu;

Received April 2021; Accepted May 2021; Published June 2021;

DOI: https://doi.org/10.31407/ijees11.332

\begin{abstract}
The development of low-cost adsorbent coal FA (Kosovo A) for pesticide removal is an important area of scientific research. With this study, we show the potential of adsorption of coal FA (Kosovo A) for removal of Benalaxyl and Atrazine from water. We have found that the amount of adsorbed Benalaxyl and Atrazine increases with an increasing amount of Coal FA (Kosovo A) in solution. The maximum capacity coal FA (Kosovo A) to adsorb Benalalaxyl and Atrazine was found to be 0.46 and $0.45 \mathrm{mg} / \mathrm{g}$ according to the Freundlich equation and 3.48 and $3.33 \mathrm{mg} / \mathrm{g}$ according to the Langmuir equation. The Freundlich adsorption equation better explains the adsorption results of pesticides (Benalaxyl and Atrazine) in Coal FA (Kosovo A), as the values of the recovery coefficient $\left(\mathrm{R}^{2}\right)$ were higher in of Freundlich equation than in the of Langmuir equation. The adsorption isotherms were of type $\mathrm{L}$ and show that the adsorption efficiency of the Coal FA (Kosovo A) depends on the initial concentration of Benalaxyl and Atrazine in solution and the maximum removal of Benalaxyl and Atrazine was achieved at concentrations less than $10 \mu \mathrm{g} / \mathrm{ml}$. This study's results are expected to have implications for the use of Coal FA (Kosovo A) for the removal of pesticides from water.
\end{abstract}

Keywords: Benalaxyl, Atrazine, Coal FA (Kosovo A), Adsorption. 